Published online: October 1, 2008 Surgesteriy

\title{
Hepatocellular Carcinoma with Hepatic Venous Obstruction and Hepatic Venous Collaterals
}

\author{
Masao Hashimoto Nobutaka Umekita \\ Department of Surgery, Tokyo Metropolitan Bokutoh General Hospital, Tokyo, Japan
}

Dynamic computed tomography of a 60 -year-old man revealed a mass, $7 \mathrm{~cm}$ in diameter, in the left liver, which was high density in the early phase (fig. 1a), and iso- to low density in the late phase (fig. 1b). The middle hepatic vein appeared compressed and obstructed by the mass, which was calculated from the following finding: in the early phase of volume-rendered coronal computed tomography, the right hepatic vein as well as the middle and the left hepatic veins were enhanced through the hepatic venous collaterals between the middle and the right hepatic veins due to the hepatic artery hepatic venous shunt via the mass (fig. 2). A left hemihepatectomy was performed combined with resection of the distal part of the middle hepatic vein. The pathologic diagnosis was hepatocellular carcinoma, with tumor invasion of the adventitia of the resected part of the middle hepatic vein, without any endoluminal invasion.

A hypervascular liver tumor causing obstruction of the hepatic veins with hepatic venous collaterals is usually a focal nodular hyperplasia, whereas hepatocellular carcinoma can also be associated with these vascular abnormalities as in the present case.
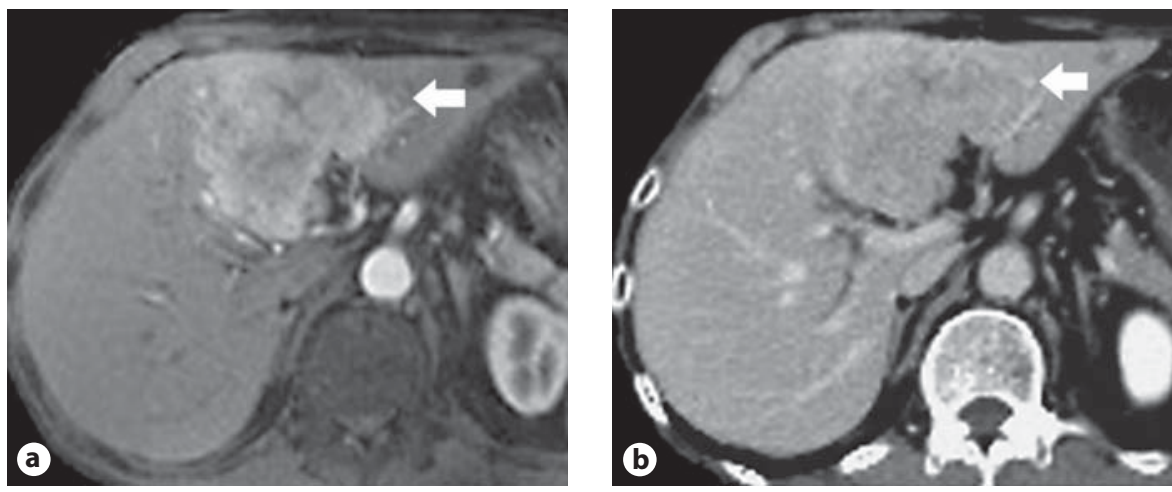

Fig. 1. Preoperative dynamic computed tomography. a In the early phase, a high-density mass (arrow), $7 \mathrm{~cm}$ in diameter, can be seen in the left side of the liver. $\mathbf{b}$ In the late phase, the mass demonstrates iso- to low density (arrow).

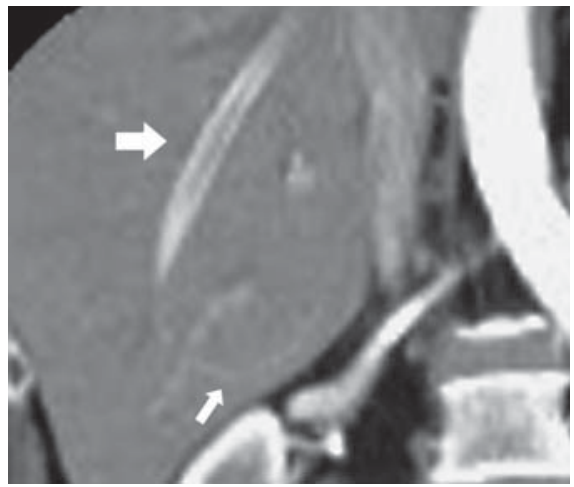

Fig. 2. Volume-rendered coronal computed tomography. In the early phase, the right hepatic vein (thick arrow) is enhanced through the hepatic venous collaterals (thin arrow) between the middle hepatic vein and the right hepatic vein.

\section{KARGER}

Fax +41613061234 E-Mail karger@karger.ch www.karger.com
Masao Hashimoto, MD

Department of Surgery, Tokyo Metropolitan Bokutoh General Hospital

4-23-15 Kohtohbashi, Sumida-ku, Tokyo 130-8575 (Japan)

Tel. +8133633 6151, Fax +81336336173

E-Mail hashimom-tky@umin.ac.jp 